\title{
Physical and Chemical Properties of Philippine Coal Blended with Torrefied Biomass from Rice (Oryza sativa) Straw
}

\author{
Rose Ann P. Lomeda-De Mesa ${ }^{1,4}$, Allan N. Soriano ${ }^{3}$, Ariziel Ruth D. Marquez ${ }^{1,2}$, and Adonis P. Adornado ${ }^{1,2,4, *}$ \\ ${ }^{1}$ School of Graduate Studies, Mapúa University, Manila 1002, Philippines \\ ${ }^{2}$ School of Chemical, Biological, and Materials Engineering and Sciences, Mapúa University, Manila 1002, Philippines \\ ${ }^{3}$ Department of Chemical Engineering, Gokongwei College of Engineering, De La Salle University, 2401 Taft Avenue, \\ Manila 1004, Philippines \\ ${ }^{4}$ General Education Department, Colegio de Muntinlupa, Mayor J. Posadas Avenue, Sucat 1770, Muntinlupa City, \\ Metro Manila, Philippines
}

\begin{abstract}
Looking at the feasibility of using rice (Oryza sativa) straw locally known as "dayami", which the Philippines is quantitatively abundant, for power generation could help farmers reduce production cost and minimize the postharvest waste. Hence, this study's objective is to provide a detailed knowledge of the physical and chemical properties of Philippine coal blended with torrefied rice (O. sativa) straw to efficiently use biomass for energy production. Proximate, ultimate, and calorific value analyses showed that rice $(O$. sativa) straw like other biomass resources are appropriate to meet the requirement of thermochemical process. When compared to pure coal, agricultural residues biomass like rice $(O$. sativa) straw has lower moisture and ash content, likewise nitrogen and sulfur are very low as well. Generally, blending Philippine coal with torrefied rice (O. sativa) straw would improve its quality in terms of its combustion properties thereby making these combinations of coal and biomass advantageous.
\end{abstract}

\section{Introduction}

According to the Philippine Rice Research Institute (PhilRice), the country produces 15.2 million tons of rice (Oryza sativa) that leave behind 11.3 million tons of rice (O. sativa) straw a year which farmers should not burn in the open field after harvest for environmental and economic reasons [1]. For that reason, there is a need to adopt proper approaches to reduce and reuse agricultural waste. In the Philippines, one coal resources is in Semirara Island located in Caluya, Antique, with an estimated total coal reserve of around 170 million metric tons [2]. However, Philippine coals are black in color, dull (not shiny), have higher moisture and volatile matter, and lower sulfur and fixed carbon content compared to other types of coal, referred to as sub-bituminous $[3,4]$. Moreover, it is classified as second lowest rank of coals due to their lower calorific value [5-7].

Utilizing and improving the quality of Philippine indigenous coal is getting more important in order to sustain the country's high dependence on coal and to ensure that the growing energy demand can also be addressed. In addition to that, the prices of oil and gas are kept on increasing, thus it is important to develop a new energy system that will serve as an alternative to the nonrenewable, highly centralized, and undiversified system by utilizing local sources of energy such as rice (O. sativa) straw used as feedstock or raw material in generating electricity $[8,9]$.
Thus, the main purpose of this work is to provide a detailed knowledge of the physical and chemical properties of Philippine coal blended with torrefied rice (O. sativa) straw through proximate, ultimate, and calorific value analyses to efficiently use biomass for energy production. This sort of study could serve to create a database of biomass fuels which would support decision making in terms of energy conversion technology selection and operating condition setting.

\section{Methodology}

\subsection{Preparation of Rice (Oryza sativa) Straw}

For this study, 3 kilograms of raw rice (Oryza sativa) straw were collected from a rice field in the Town of Calaca in the province of Batangas, Philippines. Representative rice (O. sativa) samples were taken to the Bureau of Plant Industry (BPI) for plant identification, species authentication, and certification. The raw rice $(O$. sativa) straw was reduced in size in the range of 1.0 to $1.5 \mathrm{~cm}$, and then dried using a Binder Drying Oven ED 53 at $105^{\circ} \mathrm{C}$ for 24 hours prior torrefaction. The weights of the raw and the oven-dried rice ( $O$. sativa) straw were recorded, and then the percentage of moisture removed from drying was calculated.

\footnotetext{
Corresponding author: apadornado@mapua.edu.ph
} 


\subsection{Torrefaction of Rice (Oryza sativa) Straw}

Biomass torrefaction is a mild thermochemical process that generally performed in inert atmosphere in the temperature range of 200 to $300^{\circ} \mathrm{C}$ for several minutes or hours. This treatment gained interest as it promotes an increase in the energy content of biomass to levels equal to and sometimes above that of coal [10], making it a more attractive and competitive source within the primary energy matrix [11].

The oven-dried rice (Oryza sativa) straw was torrefied using an electric Ney Vulcan 3-1750 Box Muffle Furnace equipped with thermocouple, slide out heating elements, combined fiber, and firebrick insulation for quick cooling and three-stage programmable system of temperature regulation. The 1,750 cubic inches inner volume capacity of the furnace was connected to the outer atmosphere through a tube that provides access of oxygen into the torrefaction zone and discharge of gaseous pyrolysis products.

For each run, approximately 200 grams of oven-dried rice $(O$. sativa) straw were placed into unsealed 110.45 cubic inches ceramic vessels to provide free access of oxygen. The oven-dried rice $(O$. sativa) straw was torrified at $300^{\circ} \mathrm{C}$ (heating rate of $5^{\circ} \mathrm{C} / \mathrm{min}$ ) for 30 minutes under normal atmospheric pressure. The torrefied rice $(O$. sativa $)$ straw was grinded using a Wiley mill and then sifted using a stainless steel laboratory test sieve with mesh screen no. 60 equivalent to an approximate size of $250 \mu \mathrm{m}$ to homogenize the particle size. Finally, the sifted rice $(O$. sativa) straw were collected in a clean, dry, and sealed bag, and stored in a dessicator until used for blending and characterization. The weights of the oven-dried and the torrified rice $(O$. sativa) straw were recorded, and then the percentage recovery was calculated.

\subsection{Proximate Analysis}

The proximate analysis performed for the torrefied rice (Oryza sativa) straw, Philippine coal, and its blends (\% $\mathrm{w} / \mathrm{w})-25,50$, and 75 was in accordance to ASTM D3172-13: Standard Practice for Proximate Analysis of Coal and Coke [12]. This practice covers the determination of moisture (MC), volatile matter (VM), and ash (AC) and the calculation of fixed carbon (FC). All measurements performed in this study were carried out in three replicate runs and the mean values were reported.

\subsection{Ultimate Analysis}

The ultimate analysis for the torrefied rice (Oryza sativa) straw, Philippine coal, and its blends $(\% \mathrm{w} / \mathrm{w})-25,50$, and 75 was performed using LECO CHN628 Series Elemental Determinator and CKIC 5E-S3200 Coulomb Sulfur Analyzer operated using S3200 application program to determine the carbon $(\mathrm{C}) /$ hydrogen $(\mathrm{H}) /$ nitrogen $(\mathrm{N})$ and the total sulfur (S) content, respectively.

For $\mathrm{C} / \mathrm{H} / \mathrm{N}$ determination, a $0.10 \mathrm{mg}$ of the torrified rice $(O$. sativa) straw was placed in a tin capsule, heated at $980^{\circ} \mathrm{C}$ with a constant flow of helium enriched with oxygen gas [13].
While for the total $\mathrm{S}$, on average, a $50.45 \mathrm{mg}$ of the torrified rice $(O$. sativa $)$ straw is required, and then covered with a thin layer of tungsten trioxide $\left(\mathrm{WO}_{3}\right)$ after weighing in temperature rise period. The furnace was heated to $1,150^{\circ} \mathrm{C}$ for 30 minutes before analyzing the samples. Also, average values of the triplicate runs were reported for all measurements done in this study.

\subsection{Calorific Value (Experimental)}

The experimental calorific value $(\mathrm{CV})$ of the torrefied rice (Oryza sativa) straw, Philippine coal, and its blends $(\% \mathrm{w} / \mathrm{w})-25,50$, and 75 was determined using an adiabatic CKIC 5E-AC/PL Calorimeter by completely combusting 1.00 gram of the samples under a pressurized $\mathrm{O}_{2}$ atmosphere [10]. For all combustion experiments, the samples were charged with oxygen at a pressure of 2.80 to $3.00 \mathrm{MPa}$ and a cylinder pressure of $\geq 5 \mathrm{MPa}$.

\subsection{Calorific Value (Calculated)}

The values obtained from the proximate and ultimate analyses were used to calculate the calorific value based on existing correlations taken from the literature which are applicable for both coal and biomass based on parameters for proximate and ultimate analyses as shown in Tables 1 and 2, respectively. Thus, it follows that the existing correlations presented are not specific for rice (Oryza sativa) straw alone.

Table 1. Correlations for calorific value applicable for both coal and biomass based on proximate analysis.

\begin{tabular}{|l|l|c|}
\hline \multicolumn{1}{|c|}{ Study } & \multicolumn{1}{|c|}{ Correlation for Calorific Value, $\mathbf{M J} \cdot \mathbf{k g}^{-1}$} & Eq. \\
\hline $\begin{array}{l}\text { Kavšek } \\
\text { et al. [14] }\end{array}$ & $\mathrm{CV}=0.4108 \mathrm{FC}+0.1934 \mathrm{VM}-0.021 \mathrm{AC}$ & $(1)$ \\
\hline $\begin{array}{l}\text { Kieseler } \\
\text { et al. [15] }\end{array}$ & $\mathrm{CV}=0.3536 \mathrm{FC}+0.1559 \mathrm{VM}-0.0078 \mathrm{AC}$ & $(2)$ \\
\hline $\begin{array}{l}\text { Majumder } \\
\text { et al. [16] }\end{array}$ & $\mathrm{CV}=-0.03 \mathrm{AC}-0.11 \mathrm{MC}+0.33 \mathrm{VM}+0.35 \mathrm{FC}$ & $(3)$ \\
\hline $\begin{array}{l}\text { Mesroghli } \\
\text { et al. [17] }\end{array}$ & $\mathrm{CV}=37.777-0.647 \mathrm{MC}-0.387 \mathrm{AC}-0.089 \mathrm{VM}$ & $(4)$ \\
\hline $\begin{array}{l}\text { Parikh } \\
\text { et al. [18] }\end{array}$ & $\mathrm{CV}=0.3536 \mathrm{FC}+0.1559 \mathrm{VM}-0.0078 \mathrm{AC}$ & $(5)$ \\
\hline
\end{tabular}

Table 2. Correlations for calorific value applicable for both coal and biomass based on ultimate analysis.

\begin{tabular}{|l|c|c|}
\hline \multicolumn{1}{|c|}{ Study } & Correlation for Calorific Value, $\mathbf{M J} \cdot \mathbf{k g}^{-1}$ & Eq. \\
\hline $\begin{array}{l}\text { Channiwala } \\
\text { \& Parihk } \\
{[19]}\end{array}$ & $\begin{array}{c}\mathrm{CV}=0.3491 \mathrm{C}+1.1783 \mathrm{H}+0.1005 \mathrm{~S}- \\
0.1034 \mathrm{O}-0.0151 \mathrm{~N}-0.0211 \mathrm{~A}\end{array}$ & $(6)$ \\
\hline $\begin{array}{l}\text { Friedl } \\
\text { et al. [20] }\end{array}$ & $\begin{array}{c}\mathrm{CV}=0.00355 \mathrm{C}^{2}-0.232 \mathrm{C}-2.23 \mathrm{H}+ \\
0.0512 \mathrm{CH}+0.131 \mathrm{~N}+20.6\end{array}$ & $(7)$ \\
\hline $\begin{array}{l}\text { Jenkins } \\
\text { et al. [21] }\end{array}$ & $\mathrm{CV}=-0.763+0.301 \mathrm{C}+0.525 \mathrm{H}+0.064 \mathrm{O}$ & $(8)$ \\
\hline $\begin{array}{l}\text { Sheng \& } \\
\text { Azevedo } \\
\text { et al. [22] }\end{array}$ & $\mathrm{CV}=0.3259 \mathrm{C}+3.4597$ & $(9)$ \\
\hline $\begin{array}{l}\text { Sheng \& } \\
\text { Azevedo } \\
\text { et al. [22] }\end{array}$ & $\mathrm{CV}=-1.3675+0.3137 \mathrm{C}+0.7009 \mathrm{H}+$ & $(10)$ \\
\hline $\begin{array}{l}\text { Tillman } \\
\text { [23] }\end{array}$ & $\mathrm{CV}=0.0318 \mathrm{O}^{* \mathrm{a}}$ & $(11)$ \\
\hline
\end{tabular}

${ }^{\mathrm{a}} \mathrm{O}^{*}$ is the sum of the contents of oxygen and other elements in the organic matter $\left(\mathrm{O}^{*}=100-\mathrm{C}-\mathrm{H}-\mathrm{Ash}\right)$. 


\section{Results and Discussion}

The results for the proximate analysis, ultimate analysis, and calorific value for the torrefied rice (Oryza sativa) straw, Philippine coal, and its blends $(\% \mathrm{w} / \mathrm{w})-25,50$, and 75 were summarized in Tables 3, 4, and 5, respectively.

Table 3. Results for the proximate analysis - moisture (MC), ash (AC), volatile matter (VM), and fixed carbon (FC) on the basis of concentration $(\% \mathrm{w} / \mathrm{w})$ of rice (Oryza sativa) straw.

\begin{tabular}{|c|c|c|c|c|}
\hline $\begin{array}{c}\text { Concentration } \\
\text { (\% w/w) of Biomass }\end{array}$ & $\begin{array}{c}\text { MC } \\
\mathbf{( \% )}\end{array}$ & $\begin{array}{c}\text { AC } \\
\mathbf{( \% )}\end{array}$ & $\begin{array}{c}\text { VM } \\
\mathbf{( \% )}\end{array}$ & $\begin{array}{c}\text { FC } \\
\mathbf{( \% )}\end{array}$ \\
\hline 0 & 13.04 & 36.03 & 24.19 & 26.74 \\
\hline 25 & 9.87 & 34.42 & 25.60 & 30.11 \\
\hline 50 & 6.54 & 32.76 & 27.19 & 33.51 \\
\hline 75 & 4.62 & 31.69 & 27.64 & 36.05 \\
\hline 100 & 2.00 & 30.53 & 29.03 & 38.44 \\
\hline
\end{tabular}

Table 4. Results for the ultimate analysis - carbon (C), hydrogen $(\mathrm{H})$, nitrogen $(\mathrm{N})$, and sulfur $(\mathrm{S})$ on the basis of concentration $(\% \mathrm{w} / \mathrm{w})$ of rice (Oryza sativa) straw.

\begin{tabular}{|c|c|c|c|c|}
\hline $\begin{array}{c}\text { Concentration } \\
\text { (\% w/w) of Biomass }\end{array}$ & $\begin{array}{c}\mathbf{C} \\
\mathbf{( \% )}\end{array}$ & $\begin{array}{c}\mathbf{H} \\
\mathbf{( \% )}\end{array}$ & $\begin{array}{c}\mathbf{N} \\
\mathbf{( \% )}\end{array}$ & $\begin{array}{c}\text { S } \\
\mathbf{( \% )}\end{array}$ \\
\hline 0 & 40.22 & 4.61 & 9.80 & 0.77 \\
\hline 25 & 40.86 & 4.31 & 11.22 & 0.71 \\
\hline 50 & 40.64 & 3.94 & 11.01 & 0.55 \\
\hline 75 & 38.21 & 2.95 & 10.39 & 0.40 \\
\hline 100 & 36.80 & 2.53 & 10.49 & 0.35 \\
\hline
\end{tabular}

Table 5. Results for calorific value and energy yield on the basis of concentration $(\% \mathrm{w} / \mathrm{w})$ of rice (Oryza sativa) straw.

\begin{tabular}{|c|c|c|}
\hline $\begin{array}{c}\text { Concentration } \\
(\% \mathbf{w} / \mathbf{w}) \text { of Biomass }\end{array}$ & $\begin{array}{c}\text { Calorific Value } \\
\left(\mathbf{M J} \cdot \mathbf{k g}^{-\mathbf{1}}\right)\end{array}$ & $\begin{array}{c}\text { Energy Yield } \\
\mathbf{( \% )}\end{array}$ \\
\hline 0 & 16.17 & - \\
\hline 25 & 16.37 & 60.80 \\
\hline 50 & 15.61 & 58.00 \\
\hline 75 & 15.25 & 56.65 \\
\hline 100 & 14.57 & 54.13 \\
\hline
\end{tabular}

\subsection{Proximate Analysis}

Generally, any two coals cannot just be blended. To decide to blend or not, it is very important to understand the composition of the coals that are to be blended. The linear additive rule shown in Equation (12) is used to estimate the theoretical composite value of the coal blends to show the relationship of the coal properties and the amount of that coal in the blend, where $M$ is the composite value of the parameter being estimated and $\mathrm{x}$ is the weight fraction of the components in the blend.

$$
\mathrm{M}=\mathrm{x}_{\mathrm{b}} \mathrm{M}_{\mathrm{b}}+\left(1-\mathrm{x}_{\mathrm{b}}\right) \mathrm{M}_{\mathrm{a}}
$$

A property can be considered additive when the physical property of the blend can be predicted by the relative amounts of component coals and their physical properties. The applicability of the additive property for coal blending was determined using the coefficient of determination, $\mathrm{R}^{2}$ value of at least 0.9000 [24]. Based on Figure 1, comparing the experimental values from the calculated values for moisture (MC), ash (AC), volatile matter (VM), and fixed carbon (FC) based on the linear additive rule, it showed acceptable results with minimal deviations with overall $\mathrm{R}^{2}$ value of 0.9618 . Thus, it can be established that Philippine coal blended with rice (Oryza sativa) straw were additive based on its proximate analysis parameters.

The proximate analysis involves the quantitative determination of moisture content (MC), ash content $(\mathrm{AC})$, volatile matter (VM), and fixed carbon (FC). The results for the proximate analysis for the torrefied rice $(O$. sativa) straw, Philippine coal, and its blends (\% w/w) 25,50 , and 75 was shown in Table 3 . The trends of these values were also illustrated in Figure 1 on the basis of increasing concentration $(\% \mathrm{w} / \mathrm{w})$ of rice $(O$. sativa $)$ straw.

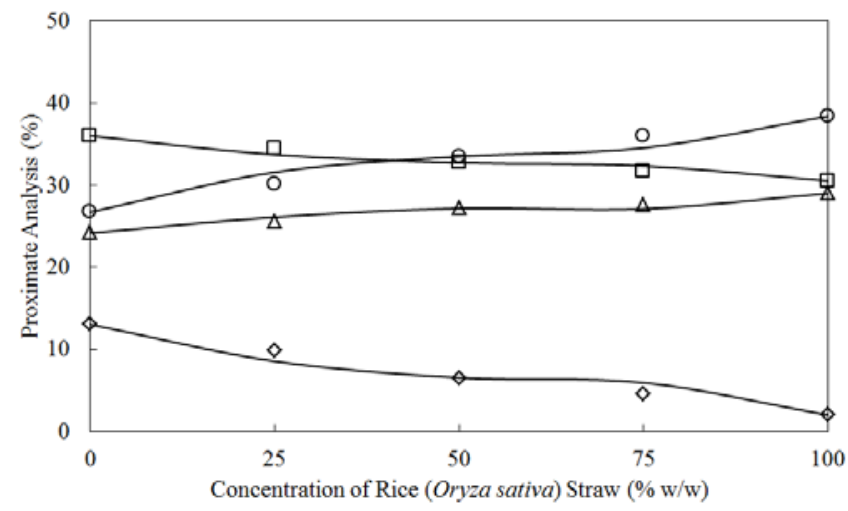

Fig. 1. Comparison of experimental values for proximate analysis parameters - moisture $(\diamond)$, ash $(\square)$, volatile matter $(\triangle)$, and fixed carbon $(\bigcirc)$ versus calculated values (solid lines) based on linear additive rule.

It was observed that an increase in the concentration of torrefied rice (O. sativa) straw in the coal blend caused a decrease in the moisture content (MC) by as much as $84.66 \%$. An increase in the moisture content of coal results in an increase in heat loss due to evaporation and superheating of vapor. Therefore, an increase in the concentration of torrefied rice (O. sativa) straw in the coal blend is a good indication that it averts the presence of fungi and decreases other biological activities upon storing. High moisture content can affect the overall energy conversion upon combustion because it influences the calorific value of the given fuel. The higher moisture content, the less energy per kilogram is released that causes lower calorific value [25]. This claim could be supported by the relationship of moisture content and calorific value of other biomass resources studied by the researchers such as for sugarcane (Saccharum officinarum) bagasse and coconut (Cocos nucifera) husk. However, for rice (O. sativa) straw, a decrease in the moisture content in the coal blend still corresponds to a decrease in the calorific value as shown in Table 5 due to the decrease in the carbon content based on ultimate analysis, which is also a predictive basis for calorific value.

Ash (AC) is the inorganic residue after combustion. One characteristic of a good fuel is having little amount 
of ash during combustion. Small amount of ash residues signifies the maximum utilization of the fuel used. High amount of ash affects combustion efficiency and boiler efficiency because it causes clinkering and slagging. Looking at Table 3, it can be observed that an increase in the amount of torrefied rice (O. sativa) straw in the coal blend would decrease the amount of ash by $15.27 \%$.

High volatile matter (VM) indicates that the fuel can be easily ignited and subsequently oxidized. High volatile matter also contributes to better efficiency for burning during combustion. It influences the secondary air requirement, distribution aspects, and secondary oil supports. An increase in the amount of torrefied rice $(O$. sativa) straw in the coal blend corresponds to an increase in volatile matter by $20.01 \%$.

Fixed carbon (FC) is the solid combustible residue that remains after a biomass particle is heated and the volatile matter is expelled. The amount of fixed carbon and volatile combustible matter directly contribute to the heating value of coal. Fixed carbon acts as a main heat generator during burning. High fixed carbon in biomass increases the char formation [25]. An increase in the amount of torrefied rice (O. sativa) straw in the coal blend also increases the amount of fixed carbon by $43.75 \%$.

Lastly, in terms of the coal blending ratios used in this study, the $25 \% \mathrm{w} / \mathrm{w}$ Philippine coal blended with $75 \%$ $\mathrm{w} / \mathrm{w}$ torrefied rice ( $O$. sativa) straw is considered to be the most favorable based on the results of the proximate analysis.

\subsection{Ultimate Analysis}

Shown in Figure 2 is the comparison of experimental values versus the calculated values based on the linear additive rule for ultimate analysis - carbon (C), hydrogen $(\mathrm{H})$, nitrogen $(\mathrm{N})$, and sulfur $(\mathrm{S})$. Just like in proximate analysis, the values are within the allowable results with slight deviations with overall $\mathrm{R}^{2}$ value of 0.9637 . Thus, it follows that Philippine coal blended with rice (Oryza sativa) straw were also additive based on its ultimate analysis parameters.

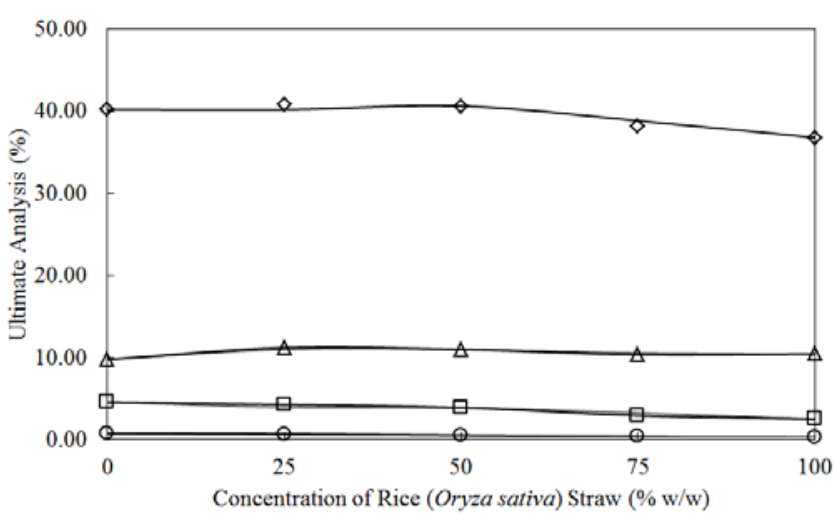

Fig. 2. Comparison of experimental values for ultimate analysis parameters - carbon $(\diamond)$, hydrogen $(\square)$, nitrogen $(\triangle)$, and sulfur $(\bigcirc)$ versus calculated values (solid lines) based on linear additive rule.
The ultimate analysis determines the elemental composition of the coal including moisture, ash, carbon $(\mathrm{C})$, hydrogen $(\mathrm{H})$, nitrogen $(\mathrm{N})$, sulfur $(\mathrm{S})$, and oxygen (O) (by difference). It is valuable in determining the quality of air required for combustion and composition of combustion gases. The results for the ultimate analysis for the torrefied rice (O. sativa) straw, Philippine coal, and its blends $(\% \mathrm{w} / \mathrm{w})-25,50$, and 75 was shown in Table 4. The trends of these values were also illustrated in Figure 2 on the basis of increasing concentration (\% $\mathrm{w} / \mathrm{w})$ of rice (O. sativa) straw.

Carbon content is a good indicative property of coal ranks. The highest rank coals have the highest carbon contents and the lowest oxygen contents. Ratios of these elements can indicate the rank of the coal and its coalification degree [26]. It is also important to measure the sulfur content in coal samples to evaluate the potential sulfur emissions from coal combustion. Increasing the amount of torrefied rice (O. sativa) straw in the coal blend decreases the carbon content by $8.50 \%$.

Meanwhile, the hydrogen content for all coal blends decreases by $45.12 \%$ with increasing amount of torrefied rice $(O$. sativa $)$ straw. The increased content of hydrogen is normally more of a characteristic of low rank coals, while the decreased values are commonly more typical for higher-rank coals [27]. Based on this, it could be said that a decrease in hydrogen content indicates that the quality of Philippine coal blended torrefied rice (O. sativa) straw improved to higher rank.

Nitrogen content for all coal blends is approximately the same with $10.58 \%$ on average. Nitrogen is an inert and incombustible gas and it does not contribute any useful property to the combustion of coal. It is generally found in the organic fraction of the coal wherein upon combustion, it is emitted as nitrogen oxide $\left(\mathrm{NO}_{\mathrm{x}}\right)$ in the flue gas.

Sulfur content for all coal blends decreases by $54.55 \%$ with increasing amount of torrefied rice (O. sativa) straw. Presence of sulfur in coal is harmful for use in metallurgy as it transfers to the metal and adversely affects the property of metal. Also, oxidation products of sulfur such as sulfur dioxide $\left(\mathrm{SO}_{2}\right)$ and sulfur trioxide $\left(\mathrm{SO}_{3}\right)$ have corrosive effect on the equipment and causes atmospheric pollution. Hence the presence of sulfur in coal is undesirable. A decrease in the sulfur content of Philippine coal upon coal blending with torrefied rice $(O$. sativa) straw is an indication that an environmentfriendly approach have been taken.

Based on the results of the ultimate analysis, considering the coal blending ratios studied, the $25 \%$ w/w Philippine coal blended with $75 \% \mathrm{w} / \mathrm{w}$ torrefied rice (O. sativa) straw is considered to be the most favorable.

\subsection{Calorific Value}

The calorific value of a fuel is the number of heat units evolved when unit mass (or unit volume in the case of a gas) of a fuel is completely burned and the combustion products are cooled to $298 \mathrm{~K}$. This definition of calorific value includes the provision that the products of combustion are cooled to $298 \mathrm{~K}$ which means the 
sensible heat and the latent heat of condensation of the water produced during combustion are included in the heat liberated. Therefore, the calorific value of the fuel is designated as 'gross calorific value (GCV)' or 'high heating values (HHV)' [28].

The energy analysis of torrefied rice (Oryza sativa) straw, Philippine coal, and its blends $(\% \mathrm{w} / \mathrm{w})-25,50$, and 75 were studied by determining the calorific value experimentally and calculating the calorific value theoretically using existing correlations found in literature applicable for both coal and biomass based on proximate and ultimate analyses as summarized in Tables 6 and 7, respectively. Also presented in these tables are the average absolute deviations (AAD) to describe variation in a data set for experimental and calculated values, and the coefficient of determination, $\left(\mathrm{R}^{2}\right)$ to measure the goodness of fit of the experimental values to the model. Here, as shown in Equation (13), the AAD is evaluated as

$$
\mathrm{AAD}=\frac{1}{n} \times \sum_{\mathrm{i}=1}^{n}\left|\left(\varepsilon_{\text {cald }}-\varepsilon_{\text {expt }}\right)\right|_{i},
$$

where $n$ is the number of data points and ( $\varepsilon_{\text {cald }}$ and $\left.\varepsilon_{\text {expt }}\right)$ are calculated and experimental values, respectively.

The carbon content in ultimate analysis was a predictive basis of the calorific value. And evidently, calorific values and the amount of carbon content show a direct proportionality since the calorific value of blended torrefied rice (O. sativa) straw and Philippine coal decreases with increasing biomass concentration (decreasing carbon content) from 16.17 to $14.57 \mathrm{MJ} / \mathrm{kg}$ or by $9.89 \%$.

Table 6. Summary results of the calorific values (experimental) for torrefied rice (Oryza sativa) straw, Philippine coal, and its blends $(\% \mathrm{w} / \mathrm{w})-25,50$, and 75 and calorific values (calculated) from literature correlations based on proximate analysis.

\begin{tabular}{|c|c|c|c|c|c|c|}
\hline \multirow{2}{*}{$\begin{array}{c}\text { Concentration } \\
\text { (\% w/w) of } \\
\text { Biomass }\end{array}$} & \multirow{2}{*}{$\begin{array}{c}\mathbf{C V}_{\text {exp. }} \\
\mathbf{M J}^{-1}\end{array}$} & \multicolumn{5}{|c|}{$\begin{array}{c}\text { Literature Correlations } \\
\mathbf{C V}_{\text {cald. }}, \mathbf{M J}^{-1} \mathbf{k g}^{-1}\end{array}$} \\
\cline { 3 - 8 } & & {$[\mathbf{1 4}]$} & {$[\mathbf{1 5}]$} & {$[\mathbf{1 6}]$} & {$[\mathbf{1 7 ]}$} & {$[\mathbf{1 8}]$} \\
\hline 0 & 16.17 & 14.91 & 12.95 & 14.83 & 13.24 & 12.95 \\
\hline 25 & 16.37 & 16.60 & 14.37 & 16.87 & 15.79 & 14.37 \\
\hline 50 & 15.61 & 18.34 & 15.83 & 19.00 & 18.45 & 15.83 \\
\hline 75 & 15.25 & 19.49 & 16.81 & 20.28 & 20.06 & 16.81 \\
\hline 100 & 14.57 & 20.76 & 17.88 & 21.90 & 22.08 & 17.88 \\
\hline OAAD (\%) & - & 6.96 & 8.70 & 4.77 & 6.00 & 8.70 \\
\hline $\mathrm{R}^{2}$ & - & 0.992 & 0.993 & 0.579 & 0.782 & 0.993 \\
\hline
\end{tabular}

Table 7. Summary results of the calorific values (experimental) for torrefied rice (Oryza sativa) straw, Philippine coal, and its blends $(\% \mathrm{w} / \mathrm{w})-25,50$, and 75 and calorific values (calculated) from literature correlations based on ultimate analysis.

\begin{tabular}{|c|c|c|c|c|c|c|c|}
\hline \multirow{2}{*}{$\begin{array}{l}\text { Concentration } \\
(\% \text { w/w) of } \\
\text { Biomass }\end{array}$} & \multirow{2}{*}{$\begin{array}{l}\mathbf{C V}_{\text {exp }} \\
\mathbf{M J} \cdot \mathbf{k g}^{-1}\end{array}$} & \multicolumn{6}{|c|}{$\begin{array}{l}\text { Literature Correlations } \\
\qquad \mathbf{C V}_{\text {calc }}, \mathbf{M J} \cdot \mathrm{kg}^{-1}\end{array}$} \\
\hline & & [19] & [20] & [21] & {$[22]^{\mathrm{b}}$} & {$[22]^{\mathrm{c}}$} & [23] \\
\hline 0 & 16.17 & 14.03 & 17.51 & 16.62 & 16.57 & 15.09 & 15.92 \\
\hline 25 & 16.37 & 14.08 & 17.92 & 16.54 & 16.78 & 15.12 & 16.20 \\
\hline 50 & 15.61 & 13.49 & $\begin{array}{l}17.89 \\
\end{array}$ & 16.35 & 16.70 & 14.86 & 16.10 \\
\hline 75 & 15.25 & 11.06 & 17.47 & 15.36 & 15.91 & 13.55 & 15.04 \\
\hline 100 & 14.57 & 9.91 & 17.37 & 14.83 & 15.45 & 12.91 & 14.42 \\
\hline AAD (\%) & - & 2.05 & 0.87 & 0.29 & 1.26 & 2.44 & 0.99 \\
\hline $\mathrm{R}^{2}$ & - & 0.995 & 0.996 & 0.996 & 0.995 & 0.995 & 0.996 \\
\hline
\end{tabular}

Considering the calorific values calculated from literature correlations based on for both proximate and ultimate analyses, the model presented by Jenkins et al. [21] has the lowest AAD value of $0.29 \%$ among the eleven correlations, at the same time the experimental values best fit with that same model, as shown in Figure 3, having an $\mathrm{R}^{2}$ value of 0.996 . The calorific value is the key parameter to evaluate the fuel quality of a special biomass material in energetic application [29]. Higher calorific value is desirable to achieve higher rank of coal. Blended biomass-coal can be predicted to be able to keep pace with pure coal in terms of calorific value.

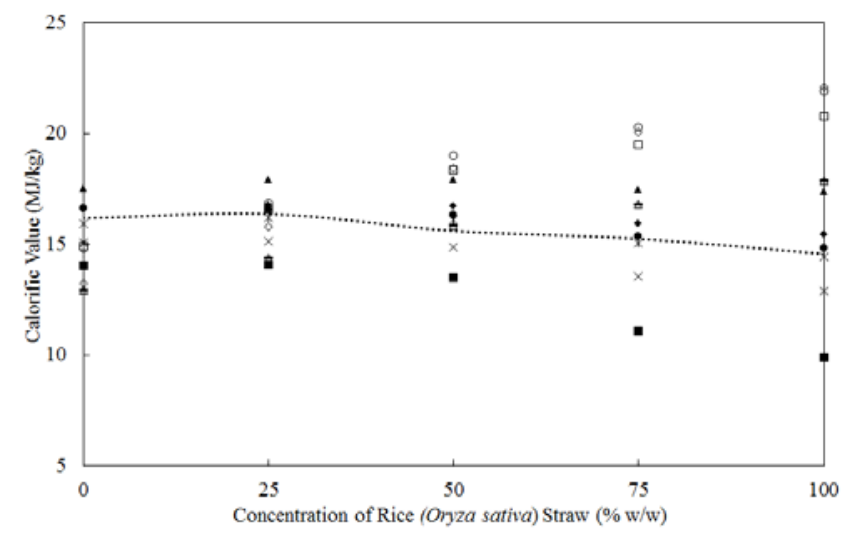

Fig. 3. Plot of experimental (dotted line) calorific values of blended Philippine coal and torrefied rice (Oryza sativa) straw fitted to various correlations applicable for both coal and biomass based on: proximate analysis - Kavšek et al. ( $\square$ ), Kieseler et al. $(\triangle)$, Majumder et al. $(\bigcirc)$, Mesroghli et al. $(\diamond)$, Parikh et al. (-); and ultimate analysis - Channiwala \& Parihk (ם), Friedl et al. (A), Jenkins et al. ( $)$, Sheng \& Azevedo ${ }^{\text {b }}$ $(\diamond)$, Sheng \& $\operatorname{Azevedo}^{\mathrm{c}}(\mathbf{X})$, Tillman (*).

\section{Conclusion}

This paper aimed to provide a detailed knowledge of the physical and chemical properties of Philippine coal blended with torrefied rice (Oryza sativa) straw through proximate, ultimate, and calorific value analyses.

Using the linear additive rule, it can be established that Philippine coal blended with torrefied rice (O. sativa) straw were additive based on its proximate and ultimate analyses parameters.

Blending Philippine coal with torrefied rice (O. sativa) straw would reduce the moisture and ash content by $84.66 \%$ and $15.27 \%$, respectively, while increasing the volatile matter by $20.01 \%$ and the fixed carbon content by $43.75 \%$. On the other hand, the carbon content decreased by $8.50 \%$, lowering the calorific value by $9.89 \%$; the hydrogen and sulfur content decreased by $45.12 \%$ and $54.55 \%$, respectively which imply that the coal blend improved to higher rank and became environment-friendly.

In terms of the coal blending ratios used in this study, the $25 \% \mathrm{w} / \mathrm{w}$ Philippine coal blended with $75 \% \mathrm{w} / \mathrm{w}$ torrefied rice ( $O$. sativa) straw is considered to be the most favorable based on the results for both proximate and ultimate analysis. Among the eleven correlations considered, the model presented by Jenkins et al. [21] 
best fit with the experimental values with $\mathrm{R}^{2}$ value of 0.996 and AAD value of $0.29 \%$.

Therefore, blending Philippine coal with torrefied rice (O. sativa) straw would generally improve its quality in terms of its combustion properties thereby making these combinations of coal and biomass advantageous.

This research was supported by the Department of Science and Technology - Engineering Research and Development for Technology (DOST - ERDT) thru a scholarship/research grant coordinated by the Mapúa University - School of Graduate Studies (GS).

\section{References}

1. Philippine Rice Research Institute (PhilRice). PhilRice to study rice straw as power source. Retrieved from http://www.philrice.gov.ph/philriceto-study-rice-straw-as-power-source/

2. J. R. Sadullo, Annual Report: Semirara Mining and Power Corporation - SEC Form 17-A (2016)

3. S. P. Schweinfurth, R. B. Finkelman, Coal - A Complex Natural Resource: An overview of factors affecting coal quality and use in the United States, 1143 (2002)

4. B. Bartok, A. F. Sarofina, Fossil Fuel Combustion: A Source Book (John Wiley \& Sons, Inc., 1991)

5. Z. Luo, M. Agraniotis, Low-rank Coals for Power Generation, Fuel and Chemical Production (Woodhead Publishing, 2017)

6. S. Lee, S. Kim, D. Chun, H. Choi, J. Yoo, Upgrading and advanced cleaning technologies for low-rank coals - Low-rank Coals for Power Generation, Fuel and Chemical Production (Woodhead Publishing, 2017)

7. European Commission - Infrastructure for Spatial Information in Europe (INSPIRE). Fossil Fuel: Low Rank Coal. Retrieved from http://inspire.ec.europa.eu/codelist/FossilFuelValue/lo wRankCoal

8. D. J. Yap (2012). Philippine Daily Inquirer. PhilRice looks into rice straw as energy source. Retrieved from https://newsinfo.inquirer.net/259548/philricelooks-into-rice-straw-as-energy-source

9. Philippine Rice Research Institute (PhilRice). Don't burn rice straw - PhilRice. Retrieved from https://www.philrice.gov.ph/dont-burn-rice-strawphilrice/

10. T. A. Mamvura, G. Pahla, E. Muzenda, SAJCE 25, 112 (2018)

11. C. M. S. da Silva, A. D. C. O. Carneiro, B. R. Vital, C. G. Figueiró, L. de Freitas Fialho, M. A. de Magalhães, A. G. Carvalho, W. L. Cândido, Renew. Sust. Energ. Rev. 82, 2426-2432 (2018)

12. ASTM D3172-13, Standard Practice for Proximate Analysis of Coal and Coke, ASTM International, West Conshohocken, PA, 2013, www.astm.org

13. Y. D. Singh, P. Mahanta, U. Bora, Renew. Energ. 103, 490-500 (2017)
14. D. Kavšek, A. Bednárová, M. Biro, R. Kranvogl, D. B. Vončina, E. Beinrohr, CEJC 11, 1481-1491 (2013)

15. S. Kieseler, Y. Neubauer, N. Zobel, Energ. Fuel. 27, 908-918 (2013)

16. A. K. Majumder, R. Jain, P. Banerjee, J. P. Barnwal, Fuel 87, 3077-3081 (2008)

17. S. Mesroghli, E. Jorjani, S.C. Chelgani, Int. J. Coal Geol. 79, 49-54 (2009)

18. J. Parikh, S. A. Channiwala, G. K. Ghosal, Fuel 84 487-494 (2005)

19. S. A. Channiwala, P. P. Parikh, Fuel 81, 1051-1063 (2002)

20. A. Friedl, E. Padouvas, H. Rotter, K. Varmuza Anal. Chim. Acta 544, 191-198 (2005)

21. B. Jenkins, L. L. Baxter, T. R. Miles Jr, T. R. Miles, Fuel Process. Technol. 54, 17-46 (1998)

22. C. Sheng, J. L. T. Azevedo, Biomass Bioenergy 28, 499-507 (2005)

23. D. A. Tillman, Wood as an Energy Resource (Elsevier 2012)

24. S. Li, N. Whitely, W. Xu, W. P. Pan, "Characterization of Coal by Thermal Analysis Methods" (2005)

25. M. A. Sukiran, F. Abnisa, W. M. A. W. Daud, N. A. Bakar, S. K. Loh, Energy Convers. Manag. 149, 101120 (2017)

26. C. Ö. Karacan, R. A. Olea, J. Geochem. Explor. 186 36-49 (2018)

27. M. A. Rasheed, P. S. Rao, A. Boruah, S. Z. Hasan, A. Patel, V. Velani, K. Patel, Geosci. J. 5, 113-119 (2015)

28. H. Liu, Biomass Fuels for Small and Micro Combined Heat and Power (CHP) Systems: Resources, Conversion and Applications. In Small and Micro Combined Heat and Power (CHP) Systems (Woodhead Publishing 2011)

29. A. Özyuğuran, S. Yaman, Energy Procedia 107, 130136 (2017) 